\title{
Realized volatility spillovers in the non-ferrous metal futures market
}

\author{
Neda Todorova ${ }^{\mathrm{a}}$, Andrew Worthington ${ }^{\mathrm{b}}$, Michael Souček ${ }^{\mathrm{c}}$ \\ ${ }^{a}$ Corresponding author \\ Griffith Business School, Griffith University \\ 170 Kessels Road, Nathan, Queensland 4111, Australia \\ Email: n.todorova@griffith.edu.au \\ Phone: +6173735 7219, Fax: +61737353719 \\ ${ }^{b}$ Griffith Business School, Griffith University \\ 170 Kessels Road, Nathan, Queensland 4111, Australia \\ Email: a.worthington@griffith.edu.au \\ ${ }^{c}$ Department of Business Administration \\ European University Viadrina \\ Große Scharrnstraße 59, 15230 Frankfurt (Oder), Germany \\ Email:soucek@europa-uni.de
}

\begin{abstract}
Abstract In contrast to energy and precious metals commodities, relatively little is known about the volatility dynamics of base (or industrial) metals commodities. To address this deficiency, this paper employs a multivariate heterogeneous autoregressive (HAR) model to consider the volatility spillovers between the five of the most liquid and important non-ferrous metals contracts (aluminium, copper, lead, nickel, and zinc) traded on the London Metal Exchange using intraday data over the period June 2006 to December 2012. This period encompasses both the surge in commodities prices associated with the burgeoning industrial demand of many emerging economies, especially China, resulting in market peaks in May 2007 and April 2008 and the subsequent negative reaction of base metals markets to the collapse of stock markets during the recent global financial crisis. The results show that the volatility series of other industrial metals appear to contain useful incremental information for future price volatility. However, the own dynamics are often sufficient for describing most future daily and weekly volatility, with the most pronounced volatility spillovers identified in the longer term. Combined together, the results in this study provide useful findings for exporter and importer countries dealing with the continuing volatility in these industrially important commodity markets.
\end{abstract}

Keywords: Volatility transmission; HAR model; Intraday data; Realized volatility; Non-ferrous base metals; London Metal Exchange.

JEL Classification: C5, G1, G15. 


\section{Introduction}

Base or industrial (nonprecious) metals (including aluminium, lead, zinc, copper, and nickel) continue to play a critically important role in industrial manufacturing and economic activity worldwide, a feature particularly pronounced given the burgeoning demand for base metals by the rapidly growing Chinese economy and the commodities boom of the 2000s. In turn, this naturally focuses attention on the enhancement of our knowledge of price discovery and other behavior in physical and derivatives markets for base metals for, among other things, hedging by producers and manufacturers and portfolio allocation decisions by investors seeking asset exposure to commodities, especially in light of continuing global economic uncertainty and volatile equity and bond markets.

However, in stark contrast to the significant volume of work on energy commodities (oil, natural gas, and electricity) and precious metals (gold, silver and platinum), computationally advanced studies using high-frequency data from base metals markets remain limited. For example, Watkins and McAleer (2004) identified just 45 articles in refereed journals over the period 1980 to 2002 focusing on the prices for industrial metals, none of which utilize intraday data. This is certainly not for a lack of important and practical topics of interest in base metals, with work recently addressing price behavior (Watkins and McAleer, 2006; Hammoudeh and Yuan, 2008; Watkins and McAleer, 2008), inventory linkages between physical spot and derivatives markets (Geman and Smith, 2013), asset price linkages and information spillovers (Wang et al., 2007; Hammoudeh et al., 2009) and the links between spot and futures markets (Liu et al., 2008; Aruga and Managi, 2011). In the area of volatility transmission, spillover patterns have also been examined across international markets in the same metal (Lien and Yang, 2009), primary and scrap metal markets (Xiarchos and Fletcher, 2009) and between currency, commodity and equity markets (Khalifa et al., 2012).

The purpose of the study is to contribute to this important but small literature by identifying volatility spillover effects between the futures of five of the most actively traded base (non-ferrous) metals contracts on the London Metal Exchange (LME), the world's largest center for trading in industrial metals accounting for more than 80 percent of global non-ferrous business. The contracts selected are for aluminium, copper, lead, nickel, and zinc.

Of course, base metal price volatility has profound impacts as far as resource policy is concerned. To start with, the collective expectation is that high price volatility will remain a feature of most of these markets in the future. This has significant implications for both exporter and importer countries, their businesses, and their governments. Exporting countries are potentially subject to rapid changes in tax revenues, investment, and economic confidence. Importing countries may suffer the negative inflationary and growth effects of excessive volatility and high prices. In response, several monetary and fiscal policies may assist governments dealing with base metal price volatility. These include the hedging of base metals revenues, inflation targeting, diversification into noncommodity markets, countercyclical fiscal policies and the establishment of stabilisation funds. These all require a complete understanding of the underlying volatility dynamics, for which this analysis is invaluable.

Our study contributes to the existing literature of commodity markets and volatility transmission in four different ways. First, to our best knowledge, volatility transmission between futures contracts for non-ferrous metals have not been previously been examined. 
Industrial metal prices are subject to both short-term price movements and longer-term price trends. In turn, short-term price movements relate to influences on demand and supply in the market, like supply disruptions (e.g. natural disasters and industrial accidents), and risk premiums arising from geopolitical tensions, economic shocks or speculative activity. In the longer term, major influential factors of commodities prices are the supply-side marginal costs of production and demand-side efficiency improvements, as well as the investment strategies of agents with a long-term perspective. Taken together, these effects along with the complementary and substitute relationships between various metals may explain why the volatility series sometimes share periods of similar behavior, while at other times each market exhibits volatility unable to be simultaneously observed in the remaining series. Against this backdrop, it is important for market participants to identify spillover patterns among the individual metals.

Second, in contrast to the multivariate generalized authoregressive conditional heteroscedasticity (MGARCH) methodology, which provides the standard econometric tool in the study of volatility transmission, we utilize a multivariate heterogeneous autoregressive model (HAR) which is able to reveal the role of volatility components established over different time periods. Extending the HAR model to a multivariate context allows for a better understanding of the spillover effects as they can be assigned to short-, mid- or long-term volatility. Importantly, the disentangling of spillover effects into daily, weekly and monthly horizons cannot be done by means of the more widely established multivariate GARCH framework. Commonly encountered in equity markets research, the application of the HAR model to commodity markets research has been rather more limited. As exceptions, Chevallier and Sévi (2011) employ the model to study the volatility of $\mathrm{CO}_{2}$ emissions, Liu and Wan (2012) apply it to oil futures and Wu (2011) focuses on grain markets. Nonetheless, to our best knowledge, no multivariate extension has been utilized for studying volatility transmission in commodity markets. An additional methodological contribution of this paper is the introduction of an orthogonalized version of a multi-asset HAR model. This helps avoid any ambiguous findings arising from potential multicollinearity emerging from a model setting within which we simultaneously consider the realized volatilities of multiple assets. The chosen approach is easy to use and considers the fact that base metals, as pointed out by Geman and Smith (2013), which exhibit marginal seasonal variation in supply and demand, do not require the imposition of any additional requirements in considering seasonal effects.

Third, by adjusting realized volatility according to the approach in Hansen and Lunde (2006), we are the first to utilize an advanced intraday data based volatility proxy that accounts for the distorting effect of microstructure noise for studying base metal market volatility. The utilization of high-frequency data is known to allow for more precise inference for univariate volatility estimation and forecasting and is thus considerably more promising for gaining insights into volatility transmission patterns than data sampled at lower frequency which provides noisy volatility estimates. Of the aforementioned studies, only Lien and Yang (2009) utilize intraday data in an application of GARCH to fiveminute futures returns in three copper markets during 2005.

Finally, our sample covers the period from June 2006 to December 2012 and hence considers volatility transmission in the light of most recent market history. This period encompasses both the surge in commodities prices associated with the burgeoning industrial demand of many emerging economies, especially China, resulting in market peaks in 
May 2007 and April 2008 and the subsequent negative reaction of metals markets to the collapse of stock markets during the recent global financial crisis. ${ }^{1}$

The remainder of the paper is structured as follows. Section 2 discusses the methodology. Section 3 presents the data. Section 4 reports the empirical results. Section 5 provides some concluding remarks.

\section{Methodology}

To measure the daily quadratic variation using intraday data we employ a realized variance measure. Realized volatility in its original form, as proposed by Andersen and Bollerslev (1998) is based on the intraday futures' prices $P_{t, i}$ observed at time intervals of fixed length. The resultant continuous intraday returns are

$$
r_{t, i}=\ln \left(\frac{P_{t, i}}{P_{t, i-1}}\right) \text { for } i>0,
$$

with the first index $t$ denoting the day of observation $t=1,2, \ldots, T$. The index $i$ denotes the time of observation on a particular day $i=0,1,2, \ldots, I$. The realized variance on a trading day $t$ is estimated by finding the total of the squared intraday returns, $\sum_{i=1}^{I} r_{t, i}^{2}$.

To account for the fact that the price process may be contaminated by market microstructure noise, which in turn may cause the realized variance to be a biased and inconsistent estimator of the nonobservable volatility, we follow the kernel-based approach in Hansen and Lunde (2006) and make following adjustment,

$$
R V_{t}=\sum_{i=1}^{I} r_{t, i}^{2}+2 \sum_{j=1}^{q}\left(1-\frac{j}{q+1}\right) \sum_{i=1}^{I-j} r_{t, i} r_{t, i+j}
$$

This estimator exhibits the comforting feature of providing always positive values for realized variance. After analyzing the autocorrelation functions of the employed intraday returns, we set $q=1$ for our study. Barndorff-Nielsen et al. (2008) discuss the asymptotic properties of the kernel-based estimator in Hansen and Lunde (2006). ${ }^{2}$

To reveal interrelationships between the second moments of our chosen financial assets, we use a multivariate version of the HAR model of Corsi (2009). Motivated by the heterogeneous market hypothesis of Müller et al. (1997) and Dacorogna et al. (1998), Corsi (2009) proposes a simple autoregressive-type model for realized volatility involving volatilities realized over different periods, based upon the premise that traders with different time horizons have a different impact on volatility. This notion is supported by the observation that volatility over longer time intervals tends to have a stronger influence on volatility over shorter time intervals than vice versa. In the default univariate version of the HAR model, volatility forecasts are linear functions of the most recent historical daily, weekly, and monthly realized volatilities. Owing to its easy application, this model

\footnotetext{
${ }^{1}$ See Humphreys (2010) for a retrospective on the boom and subsequent crash in global metals markets in the 2000s.

${ }^{2}$ For alternative adjustment approaches for microstructure noise, see, for example, Bandi and Russell (2006), Oomen (2005), Zhang et al. (2005) and Zhou (1996).
} 
enjoys broad support in the plethora of modeling and forecasting techniques of financial markets volatility.

In contrast, the literature using a multivariate HAR framework is rather more limited. Bauer and Vorkink (2011), for instance, propose a matrix-logarithm model of the realized covariance matrix of stock returns. Elsewhere, Bubák et al. (2011) use a vector HAR, to analyze realized volatility transmission between Central European currencies and the EUR/USD foreign exchange rate from 2003 to 2009. In particular, they extend the oneasset HAR by incorporating historical volatility of all exchange rates under consideration into a single transmission model for the one-step ahead daily volatility. To investigate the potential volatility transmission patterns in the LME non-ferrous metals markets, we modify the multivariate framework of Bubák et al. (2011) and also include the weekly and monthly volatilities as endogenous variables.

First, to obtain a feeling for the realized volatility dynamics, we study the explanatory power of the own volatility components of daily, weekly and monthly horizons in a standalone HAR model for each of the metals considered,

$$
\sigma_{t+1, t+h}^{i}=\alpha_{0}+\alpha_{1} \sigma_{t}^{i}+\alpha_{2} \sigma_{t-4, t}^{i}+\alpha_{3} \sigma_{t-21, t}^{i}+\epsilon_{t}^{i}, \quad h=1,5,22,
$$

where $\sigma^{i}$ denotes the logarithmic realized variances $(\ln R V)$ of asset $i$. More precisely, $\sigma_{t-N, t}$ represents the normalised sum of historical daily log variances,

$$
\sigma_{t-N, t}=\frac{1}{N} \sum_{i=0}^{N} \sigma_{t-i}, \quad N=4,21 .
$$

and $\sigma_{t+1, t+h}$ is the normalized sum of the future logarithmic daily realized variances. We use the logarithmic specification of the realized variance rather than volatility itself because the distribution of logarithmic variance is known to be closer to normal, which is considered beneficial for statistical purposes. Moreover, using variance in its log form does not impose nonnegativity constraints for estimation purposes.

To identify whether there is information relevant for the future volatility of a futures contract inherent in the time series of the remaining industrial metal futures and incremental to the informational content of the own historical volatility, we subsequently run bivariate models for every asset. In total, this yields one standalone (for comparison purposes) and four bivariate regressions per asset and forecasting period. With five assets and daily, weekly and monthly variances as dependent variables, this results in 75 bivariate models.

The realized volatilities of financial assets are often highly correlated. To ensure that we only consider new information from the volatility of the second asset, we use an orthogonalized version of the vector HAR model of Bubák et al. (2011). More specifically, we first run the following time series regressions for every asset in the transmission model,

$$
\sigma_{t-k, t}^{j}=c^{j}+\alpha^{j, i} \sigma_{t-k, t}^{i}+\omega_{t-k, t}^{j, i}, \quad k=0,4,21 .
$$

If, for example, $\sigma_{t-4, t}^{j}$ is the lagged weekly volatility component of asset $j$, the residual $\omega_{t-4, t}^{j, i}$ describes the variation of $\sigma_{t-4, t}^{j}$ which is not explained by the time series of the weekly realized volatility of asset $i$.

To examine the volatility spillovers across the LME metal futures, we then extend 
the stand-alone HAR models (3) to bivariate models involving a second asset, $j$. In the bivariate case of assets $i$ and $j$, the estimated equation for the asset $i$ is

$$
\begin{aligned}
\sigma_{t+1, t+h}^{i}= & \alpha_{0}+\alpha_{1} \sigma_{t}^{i}+\alpha_{2} \sigma_{t-4, t}^{i}+\alpha_{3} \sigma_{t-21, t}^{i} \\
& +\alpha_{4} \omega_{t}^{j, i}+\alpha_{5} \omega_{t-4, t}^{j, i}+\alpha_{6} \omega_{t-21, t}^{j, i}+\epsilon_{t}, \quad h=1,5,22 .
\end{aligned}
$$

Subsequently, we select the elements of the additional volatility terms in the bivariate models that are statistically significant at least at the $10 \%$ level and consider them all in a single model per asset and future time horizon to identify the driving force of the potential volatility spillovers. A major question here is whether the individual metals contain identical information sets or whether joint consideration may enhance the explanatory power of the bivariate models.

In the full regressions, the own-volatility components are considered in full magnitude and the additional assets are presented as orthogonalized elements. For clarity within the all-asset models, the results are always presented in an alphabetic order for the considered metals, with $A$ for aluminium, $C$ for copper, $L$ for lead, $N$ for nickel, and $Z$ for zinc. For example, the following expression is the full model form for the realized volatility forecasts of the lead futures,

$$
\begin{aligned}
\sigma_{t+1, t+h}^{L}= & \alpha_{0}+\alpha_{1, A} \omega_{t}^{A, L}+\alpha_{2, A} \omega_{t-4, t}^{A, L}+\alpha_{3, A} \omega_{t-21, t}^{A, L} \\
& +\alpha_{1, C} \omega_{t}^{C, L}+\alpha_{2, C} \omega_{t-4, t}^{C, L}+\alpha_{3, C} \omega_{t-21, t}^{C, L} \\
& +\alpha_{1, L} \sigma_{t}^{L}+\alpha_{2, L} \sigma_{t-4, t}^{L}+\alpha_{3, L} \sigma_{t-21, t}^{L} \\
& +\alpha_{1, N} \omega_{t}^{N, L}+\alpha_{2, N} \omega_{t-4, t}^{N, L}+\alpha_{3, N} \omega_{t-21, t}^{N, L} \\
& +\alpha_{1, Z} \omega_{t}^{Z, L}+\alpha_{2, Z} \omega_{t-4, t}^{Z, L}+\alpha_{3, Z} \omega_{t-21, t}^{Z, L}+\epsilon_{t+1, t+h}^{L}, \quad h=1,5,22 .
\end{aligned}
$$

As discussed, in conducting the regression, only the statistically significant components of the corresponding bivariate regressions are considered and all remaining coefficients are set equal to zero.

Given the volatility of volatility is also thought to exhibit clustering effects, Corsi et al. (2008) propose an extension of the HAR model by modeling the residuals in a GARCH setting. This approach yields consistently stable parameter estimates in our study only for the next day's volatility as the dependent variable. For $h=5,22$, we encounter problems with nonconvergency or negative parameter estimates for the variance equation. In addition, the conventional HAR model and the GARCH effect-augmented residuals did not allow for qualitatively different results. Hence, to maintain consistency in the presentation of our findings, we report results for all forecast horizons obtained by the HAR model of Corsi (2009). Furthermore, consistent with other studies utilizing the HAR model (Andersen et al., 2007; Bubak et al., 2011; Corsi, 2009; Corsi and Renó, 2012; Corsi et al., 2012; Giot and Laurent, 2007), we report our findings obtained with OLS and a Newey-West correction of the standard errors accounting for the overlap of the time windows under consideration. ${ }^{3}$

\footnotetext{
${ }^{3}$ For robustness, we additionally ran the analysis with GLS, achieving very similar results.
} 


\section{Data}

Our empirical analysis employs the five-minute intraday returns of 3-month LME futures. We chose these 3-month contracts, originally designed to reflect the physical shipping time needed for delivering metal stocks to London, because they are the LME's (and therefore the world's) most-liquid metals futures contracts (Geman and Smith, 2013; Watkins and McAleer, 2004). It is important to note that LME contracts are not conventional futures contracts in many respects. Futures prices on the LME are quoted for fixed maturities, that is, there is a new contract for each business day. For example, there is a 3-month futures price quoted on each business day, and for each trading day, there is a new contract with a maturity of 3 months, similar to longer-term contracts which are also quoted for most metals on the exchange, though the 3-month contracts are the most liquid in each metals market. The futures prices are in US dollars per ton. The data originate from the exchange operated electronic trading platform LMEselect and are obtained from the Thomson Reuters Tick History database at the Securities Industries Research Centre of Asia Pacific (SIRCA). The daily transaction records extend from 1:00 to 19:00 GMT. The sample data cover the period of six years and seven months from June 1, 2006 to December 31, 2012, representing 1,663 trading days. We selected the starting point of the sample to avoid any potential structural break in the level of realized volatility owing to the fact that before June 2006 the trading time was shorter than 18 hours per day on this trading platform.

We exclude overnight returns and data from weekends and public holidays from the sample. A final note concerns the issue of potential nonsynchronicity owing to different trading times for the considered assets. As the data emerge from the same market place, the analysis does not need to cope with the issues of overlapping trading and nontrading times as well as the impact of deviating public holidays for the individual securities under consideration.

Table 1 provides key statistics related to the annualized daily volatility and the logarithmic realized variance of the considered metals. To obtain a better sense of the magnitude of the attained estimates, we utilize the annualized form of realized variance, $252 \cdot R V_{t}$. Considering the skewness and kurtosis of the volatility series, the logarithmic specification appears to be much closer to normal distribution, as expected, as compared with the daily realized volatilities.

\section{Results}

\subsection{Stand-alone models}

We start by looking at the stand-alone HAR models for the five metals as per equation (3). The results for the one day, one week and one month forecasting horizons are presented in the left-hand side panels (the second and third columns) of Tables 2 to 6 .

As shown, it is clear that all parameter estimates for the own daily, weekly and monthly historical volatility components are positive and statistically significant at the $1 \%$ level. While in most cases, the last day's realized volatility is assigned a high weight for onestep ahead forecasts, the weekly and monthly components become increasingly important for establishing mid- and longer-term forecasts across all assets. The coefficient of the monthly component exhibits a comparatively very high magnitude for lead, nickel, and zinc. In contrast, the highest relevance for the copper futures volatility is inherent in the 
historical weekly volatility series for all forecasting periods. In the case of aluminium, the coefficient of the mid-term volatility is similar to the daily volatility for shorter-term forecasts and close to that of the monthly volatility for longer horizons.

We next note the relatively high explanatory power (as measured by $R_{A d j}^{2}$ ) across the models, ranging from 0.644 for the monthly volatility of aluminium to 0.836 for the weekly volatility of copper futures. It is worth noting that the HAR models exhibit consistently highest explanatory power for mid-term horizons. Against the backdrop of this strong forecasting power, it is interesting to explore whether the volatility time series of other assets potentially adds explanatory power to the models.

\subsection{Bivariate models}

Tables 2 to 6 provide the results of the bivariate models. These findings show whether there is additional information about the next day's, week's and month's volatility of each non-ferrous metal's futures inherent in the realized variance series of the futures contracts on the other metals in the same market.

Starting with the one-step ahead daily volatility, we discern no significant parameter estimates for the time series of aluminium futures volatility. While the short-term realized volatilities of lead and nickel are significant for copper and the various components of the remaining metals appear to be relevant in the case of lead and zinc, the explanatory power of the bivariate models in terms of adjusted $R^{2}$ scarcely increases by more than 0.005 . The exception is nickel, for which the daily and monthly components of lead futures are both positive and the adjusted $R^{2}$ increases by 0.011 .

A similar picture emerges for the one-week forecasting horizon. Despite the existence of significant parameters for most of the short-term volatility components, the gain in explanatory power is lower than 0.01 in most cases. Notably, the highest contribution is made again by including both short- and long-term volatility of lead futures into the model for the realized volatility of nickel $\left(\Delta R_{A d j}^{2}=0.022\right)$. Other than this, the mid-term time series of copper and zinc volatility seem to contain incremental information to that inherent in the nickel own series, with $\Delta R_{A d j}^{2}$ being 0.01 and 0.011 , respectively.

When we shift our focus to monthly horizons, we encounter a different picture. The largest gain in explanatory power arises from incorporating all three lead volatility components $\left(\Delta R_{A d j}^{2}=0.064\right)$ and short- as well as long-term zinc $\left(\Delta R_{A d j}^{2}=0.029\right)$ volatility time series into the model for nickel. For the aluminium futures, a notable increase compared to the stand-alone HAR is observed for all bivariate models, emerging especially from the long-term volatility components of the other metals with $\Delta R_{\text {Adj }}^{2}$ ranging from 0.011 for copper to 0.033 for lead. For copper, the long-term lead volatility appears to contain the most informational set for copper $\left(\Delta R_{A d j}^{2}=0.016\right)$. With lower gains in explanatory power, but still above 0.015 , the zinc futures volatility appears to be related with short- as well as long-term copper and aluminium volatility. The exception is lead futures volatility which seems to add significant information to the longer-term forecasts of all other metals but remains unaffected by them.

\subsection{Full models}

The results presented in the previous subsection imply the presence of spillover effects in the non-ferrous metals markets, especially over long-term horizons. The various metal futures contracts also appear to contain incremental information, especially for the 
volatility of nickel, copper, and zinc. However, one limitation of the bivariate models is that they do not allow us to identify which of the asset price series is the driving force for the spillovers. In other words, if more than one additional futures contract is capable of adding useful information about future metal volatility, we may consider overlapping information sets or deploying multiple assets into a single transmission model to gain additional explanatory power.

To respond to this question, we report the estimation results for the all-assets transmission models in which the right-hand side variables in the bivariate models that are not significant at least at the $10 \%$ level have been successively eliminated in Tables 7 to 8. In these models which generally allow for considering all five metals, the asset's own volatility components are presented as in equation (4) while the volatilities of the remaining four assets are considered as orthogonilazed transformations, according to equation (5). The regression parameters are assigned to the metals in an alphabetical order with $\alpha_{1, X}$ (daily), $\alpha_{2, X}$ (weekly) and $\alpha_{3, X}$ (monthly) and $X=A$ (aluminium), $C$ (copper), $L$ (lead), $N$ (nickel) and $Z$ (zinc). $R_{A d j, E n c}^{2}$ denotes the adjusted $R^{2}$ of the full models and $R_{A d j, S}^{2}$ established with the stand-alone regressions are reported for comparison purposes.

Similar to the results of the bivariate models, the own-volatility components exhibit without exception positive and statistically significant coefficients with the highest $t$-values per transmission model. Starting with the one-step ahead daily volatility, the results from the stand-alone model for aluminium are identical to these in Table 2 since the bivariate regression did not indicate any spillover effects from other metal futures. Hence, a flexible framework allowing for considering all assets does not yield a significant gain for any of the metals. Shifting our attention to the remaining transmission models for daily and weekly volatility, we can see that the additional explanatory power for one-step ahead nickel volatility emerges solely from short- and long-term lead volatility whereas shortterm copper volatility contains some information about mid-term nickel forecasts, which go beyond the informational set of lead. For all other metals, only minor improvements for daily and weekly volatility are found suggesting that for short- and mid-term volatility, the own dynamics contain most of the sufficient information which may be extracted by a HAR methodology with the given specification.

Once again, specifying the future monthly volatility as the dependent variable on the right-hand side of the full transmission models reveals a different picture. As for the aluminium variance equation, we note that other than its own three variance components, both the long-term lead and mid-term nickel volatility affect the monthly volatility resulting in a higher $R_{A d j, E n c .}^{2}$ (0.735) than the corresponding bivariate models (0.678 and 0.672 , respectively).

The long-term component of lead futures volatility is furthermore identified as a driving force of the spillover effects concerning copper and nickel. The results for the copper equation reveal that the single source of the spillovers, identified with the bivariate models, is the long-term volatility of lead futures with a corresponding coefficient estimate reading $\alpha_{3, L}=0.378$. In contrast, besides the monthly lead component, short-term copper and mid-term lead volatility play additionally a significant role and obviously contain complementary information sets in the equation of the nickel log monthly variance. The largest number of significant spillover effects is documented for zinc where they emerge from short-term lead and copper volatility, as well as from long-term aluminium and copper volatility. 
Finally, the results for the lead variance equation confirm the previous conclusion that nearly no spillover effects can be identified for lead futures volatility. Indeed, positive and strongly significant coefficients are documented for short-term zinc volatility $\alpha_{1, Z}$ but for

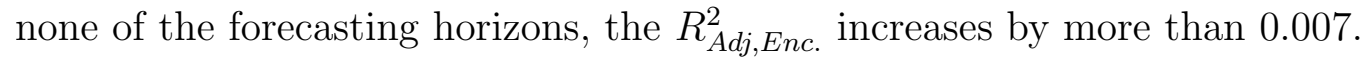

\subsection{Discussion}

Aluminium and copper contracts generally account for the largest volume of spot and futures trade on the LME. These metals are also among the most important metals industrially and the course of their prices often closely relates to developments in global industrial production (Watkins and McAleer, 2008). Against this backdrop, it is a particularly surprising and important finding that the volatility series of other industrial metals appear to contain incremental information about future aluminium and copper volatility.

Our second major result concerns the fact that even if there is variation in the other metals' volatility series which cannot be explained by their own volatility, the short- and mid-term volatility of all industrial metals remains less affected by including this additional information into a HAR model. This observation implies that the own dynamics are sufficient for describing most future daily and weekly volatility. In contrast, pronounced spillovers can be identified at the level of long-term volatility. This is a plausible result indicating that complementary and substitute relationships between metal futures, which are mostly demanded by manufacturing companies with longer-term goals than other market participants play a more significant role in the volatility of the individual metals. The spillover emerging from nickel volatility to the long-term price variation of aluminium futures may be ascribed, for example, to the relevance of both metals for the automobile industry, which is also the major application area for nickel. Similarly, the construction of infrastructure could be the source of the spillovers from the aluminium and copper to the zinc futures market and the demand for copper and lead for the production of electronic and electrical components may invoke the dependence of copper on long-term lead volatility.

It is important to note that the identified transmission does not consistently follow a straightforward pattern allowing for the derivation of a general rule concerning long-term dependencies only. In the case of zinc, for example, the statistically significant negative coefficients for long-term aluminium and copper volatility, as opposed to the positive estimates of the corresponding short-term volatilities, imply that it is not the absolute volatility magnitude but rather the spread between the most recent volatility and its longer-term average level that may be the most relevant information source.

The line of argument advocating that the relationships between metal futures are primarily due to joint areas of industrial usage appears to break down when introducing the variation of lead futures into our framework. Even if lead cannot be considered as important in the industrial sense as copper and aluminium, its volatility appears to play an important role in explaining the future long-term variation of all remaining metals. Furthermore, these spillovers turn out to be of a unidirectional nature given, despite the documented significant parameter coefficients for zinc and nickel, the explanatory power of the transmission models for lead remains barely affected by adding any of the metals to the stand-alone HAR for all three horizons. We can see that the rationale for this phenomenon is the fact that the lead market exhibits large shortages due to comparatively slower mine expansions during times of record consumption, especially during the post financial 
crisis period (Bloomberg, 2012). This is a long-lasting, accelerating phenomenon which cannot be compensated for by the high recycling rate of lead nor can be observed to this same extent for the other metals under consideration. For example, as at the beginning of February 2013, Bloomberg reports an outlook for Natixis Commodity Markets Ltd. predicting that the price of lead will increase by $24 \%$ in 2013, while copper's average price is estimated to rise by only $6.9 \%$. Aluminium, nickel and zinc are predicted to gain by 3.6\%, 6.6\% and 9.4\%, respectively (Bloomberg, 2013). Thus, the lead price dynamics reflect an overwhelming demand opposed to an insufficient supply and cannot be complemented by the informational content of other industrial metals. Besides, the lead futures' volatility may be marked by a higher sensitivity to the development of the aggregate industrial demand. Anticipating the rhythm of future global economic growth in a more efficient way, it moreover heads the long-term variation of the remaining industrial metals.

\subsection{Subsample analysis}

As our dataset covers a period of 6 years and seven months, spanning the Global Financial Crisis, we also tested the log realized volatility series for structural breaks. Using the Chow test, we indeed identified the existence of a structural break placed roughly equally in the series of all base metals in the first half of 2008. In a next step, we ran the analysis for the pre-crisis and crisis period separately to gain further insights into the source of the observed volatility transmission effects.

The subsample results (not shown) reveal a clear picture. Volatility transmission can be observed in the LME base metal market both before and during the financial crisis. This is in line with the notion that the complementary and substitutionary relationships between the metals drive the existing spillover effects. Up until 2008, we find evidence of incremental explanatory power when extending the HAR model to a multivariate framework but it is overall of weaker magnitude than thereafter. In this first part of the sample, the spillovers are, similarly to the relative importance of the own longer-term components, mostly related to the mid- or long-term volatility component of the additional assets in the HAR multivariate models. However, when considering the crisis period and its aftermath, we see that the own as well as other asset short-term volatility components gain in importance. This has a straightforward intuition. During comparatively "quieter" times, the main determinants are the longer-term volatility trends whereas during periods of higher volatility, the interrelation between the realized volatilities is increasingly driven by the short-term shocks.

The reported tabulated results for the whole sample are for the most part very similar to these from the second sample period. This is not surprising given the disproportionately shorter length of the pre-crisis period. This results in the second period's transmission patterns dominating the estimation results. For this reason, we omit the presentation of the results for both subsample periods.

\section{Conclusion}

This study uses a multivariate HAR model to consider the volatility spillovers between five non-ferrous metals contracts (aluminium, copper, lead, nickel, and zinc) traded on the London Metal Exchange using intraday data over the period June 2006 to December 2012. The use of an advanced econometric technique combined with high-frequency data means 
that we can obtain useful and robust insights into the short-, medium-, and long-term volatility dynamics in and between these markets. The realized volatility estimator based on intraday data covers a substantially larger extent of the underlying price process and subsumes by nature a more comprehensive information set than returns sampled at a daily or lower frequency. The chosen methodology using a multivariate HAR model is novel for commodity markets and allows for assigning the identified spillovers to different time horizons, which cannot be done by means of the widely established multivariate GARCH framework. We interpret the results against the backdrop of the plausible complementary and substitutionary relationships between base metal futures. The findings of such an analysis are important for exporter and importer countries dealing with the continuing volatility in these industrially important commodity markets as well as for the increasing number of cross-asset investors.

We find that the volatility series of other industrial metals appear to contain incremental information about future aluminium and copper volatility. We also find that even if there is variation in the other metal's volatility series that cannot be explained by their own volatility, the short and mid-term volatility of the industrial metals remains less affected, in term of incremental explanatory power of the estimated models, by including this additional information. However, in the long-term, we identify significant volatility interrelationships. Furthermore, the spillover effects hold during both the pre-crisis and the crisis periods in our sample. We link these with the complementary and substitutionary relationships between metals in industrial production, as ultimately reflected in the prices of their derivatives.

Of course, this study has some limitations, all of which suggest areas for future research. We use the standard form of the HAR model presenting future volatility as a function of daily, weekly and monthly historical volatilities which leads to significant results but alternative time horizons may be able to shed further light on the volatility transmission mechanisms. The analysis follows the widely established HAR model approach also in assigning equal weights to all historical daily volatilities for establishing normalized sums. A weighting scheme putting stronger emphasis on more recent volatility or on days with heavier trading activity can be considered as well. Furthermore, due to its flexibility, the current technique may be applied easily for studying volatility transmission between non-ferrous metal and other resource markets, an issue of major importance especially for portfolio allocation decisions of investors increasingly seeking asset exposure to commodities.

Andersen, T.G., Bollerslev, T., 1998. Answering the skeptics: Yes, standard volatility models do provide accurate forecasts. Int. Econ. Rev. 39, 885-905.

Andersen, T.G., Bollerslev, T., Diebold, F.X., 2007. Roughing it up: Including jump components in the measurement, modeling and forecasting of return volatility. Rev. Econ. Stat. 89, 701-720.

Aruga, K., Managi, S., 2011. Price linkages in the copper futures, primary, and scrap markets. Resour. Conservat. Recycl. 56, 43-47.

Bandi, F., Russell, J.R., 2006. Separating microstructure noise from volatility. J. Financ. Econ. 79, 655-692. 
Barndorff-Nielsen, O., Hansen, P., Lunde, A., Shephard, N., 2008. Designing realised kernels to measure the ex-post variation of equity prices in the presence of noise. Econometrica $76,1481-1536$.

Bauer, G. H., Vorkink, K., 2011. Forecasting multivariate realized stock market volatility. J. Econometrics 160, 93-101.

Bloomberg, 2012. http://www.businessweek.com/news/2012-10-11/lead-tops-metalreturns-as-shortages-set-to-emerge-commodities\#p1, accessed on 02/08/2013.

Bloomberg, 2013. http://www.bloomberg.com/news/2013-02-06/natixis-sees-industrialmetals-climbing-as-gold-begins-decline.html, accessed on 02/08/2013.

Bubák, V., Kočenda, E., Žikeš, F., 2011. Volatility transmission in emerging European foreign exchange markets. J. Ban. Fin. 35, 2829-2841.

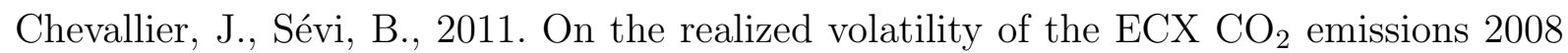
futures contract: Distribution, dynamics and forecasting. Ann. Finance 7, 1-29.

Corsi, F., 2009. A simple approximate long-memory model of realized volatility. J. Fin. Econometrics 7, 174-196.

Corsi F., Audrino F., Renó R., 2012. HAR Modeling for realized volatility forecasting. In: Bauwens, L., Hafner, C., Laurent, S. (Eds.), Handbook in Financial Engineering and Econometrics: Volatility Models and Their Applications. Wiley, New Jersey, pp. $363-382$.

Corsi, F., Mittnik, S., Pigorsch, C., Pigorsch, U., 2008. The volatility of realized volatility. Econometric Rev. 27, 46-78.

Corsi F., Renó R., 2012. Discrete-time volatility forecasting with persistent leverage effect and the link with continuous-time volatility modeling. J. Bus. Econ. Stat. 30, 368-380.

Dacorogna, M., Müller, U., Dav, R., Olsen, R., and Pictet, O., 1998. Modelling short-term volatility with GARCH and HARCH models. In C. Dunis and B. Zhou (Eds.), Nonlinear Modelling of High Frequency Financial Time Series (pp. 161-176). Chichester, UK: Wiley.

Geman, H., Smith, W.O., 2013. Theory of storage, inventory and volatility in the LME base metals. Resour. Pol. 38, 18-28.

Giot, P., Laurent, S., 2007. The information content of implied volatility in light of the jump/continuous decomposition of realized volatility. J. Futures Market. 27, 337-359.

Hansen, P.R., Lunde, A., 2006. Realized variance and market microstructure noise. J. Bus. Econ. Stat. 24, 127-218 (with comments and rejoinder).

Hammoudeh, S.M., Yuan, Y., 2008. Metal volatility in presence of oil and interest rate shocks. Energ. Econ. 30, 606-620.

Hammoudeh, S.M., Yuan, Y., McAleer, M., 2009. Modeling exchange rate and industrial commodity volatility transmissions. Working Paper Series, University of Poveda, Italy. 
Humphreys, D. 2010. The great metals boom: A retrospective. Resour. Pol. 35, 1-13.

Khalifa, A.A.A., Hammoudeh, S., Otranto, E., Ramchander, S., 2012. Volatility transmission across currency, commodity and equity markets under multi chain regime switching: Implications for Hedging and Portfolio Allocation. CRENoS Working Paper 2012/14.

Lien, D., Yang, L., 2009. Intraday return and volatility spill-over across international copper futures markets. Int. J. Manag. Financ. 5, 135-149.

Liu, X., Cheng, L., Wang, L., Hong, Y., Lib, Y., 2008. An empirical study on information spillover effects between the Chinese copper futures market and spot market. Phys. Stat. Mech. Appl. 387, 899-914.

Liu, L., Wan, J., 2012. A study of Shanghai fuel oil futures price volatility based on high frequency data: Long-range dependence, modeling and forecasting. Econ. Model. 29, 2245-2253.

Müller, U., Dacorogna, M., Dav, R., Olsen, R., Pictet, O., Weizsacker, J.v., 1997. Intraday trading volume and return volatility of the DJIA stocks: A note. J. Bank. Finance 27, $2035-2043$.

Oomen, R.C.A., 2005. Properties of bias-corrected realized variance under alternative sampling schemes. J. Financ. Econometrics 3, 555-577.

Wang, S.-N., Pan, Y., Yang, J., 2007. Study on spillover effect of copper futures between LME and SHFE using wavelet multiresolution analysis. J. Zhejiang Univ. Sci. A 8, 1290-1295.

Watkins, C., McAleer, M., 2004. Econometric modelling of non-ferrous metal prices. J. Econ. Surv. 18, 651-701.

Watkins, C., McAleer, M., 2006. Pricing of non-ferrous metals futures on the London Metal Exchange. Appl. Fin. Econ. 16, 853-880.

Watkins, C., McAleer, M., 2008. How has volatility in metals markets changed? Math. Comp. Sim. 78, 237-249.

Wu, F., 2011. Testing for volatility changes in grain markets. Paper presented at the Agricultural \& Applied Economics Association's 2011 AAEA \& NAREA Joint Annual Meeting, Pittsburgh, Pennsylvania, 2011.

Xiarchos, I.M. Fletcher, J.J., 2009. Price and volatility transmission between primary and scrap metal markets. Resour. Conservat. Recycl. 53, 664-673.

Zhang, L., Mykland, P.A., Ait-Sahalia, Y., 2005. A tale of two time scales: Determining integrated volatility with noisy high-frequency data. J. Am. Stat. Assoc. 100, 13941411.

Zhou, B., 1996. High-frequency data and volatility in foreign-exchange rates. J. Bus. Econ. Stat. $14,45-52$. 


\section{Appendix}

Table 1: Descriptive statistics for daily realized volatilities and logarithmic realized variances

\begin{tabular}{|c|c|c|c|c|c|c|c|c|c|c|}
\hline & \multicolumn{5}{|c|}{ Realized Volatility } & \multicolumn{5}{|c|}{ Log of Realized Variance } \\
\hline & Alu & Copper & Lead & Nickel & Zinc & Alu & Copper & Lead & Nickel & Zinc \\
\hline Mean & 0.254 & 0.299 & 0.398 & 0.399 & 0.385 & -2.843 & -2.591 & -2.004 & -1.989 & -2.050 \\
\hline Std. Dev. & 0.084 & 0.142 & 0.169 & 0.178 & 0.151 & 0.622 & 0.799 & 0.791 & 0.754 & 0.756 \\
\hline Minimum & 0.096 & 0.082 & 0.094 & 0.121 & 0.112 & -4.683 & -4.992 & -4.739 & -4.219 & -4.384 \\
\hline Maximum & 0.894 & 1.528 & 1.491 & 1.665 & 1.399 & -0.224 & 0.848 & 0.799 & 1.020 & 0.672 \\
\hline Skewness & 1.354 & 2.279 & 1.556 & 2.308 & 1.375 & 0.278 & 0.584 & 0.166 & 0.566 & -0.051 \\
\hline Kurtosis & 3.949 & 8.560 & 4.297 & 8.695 & 4.140 & -0.067 & 0.535 & 0.020 & 0.670 & 0.075 \\
\hline
\end{tabular}




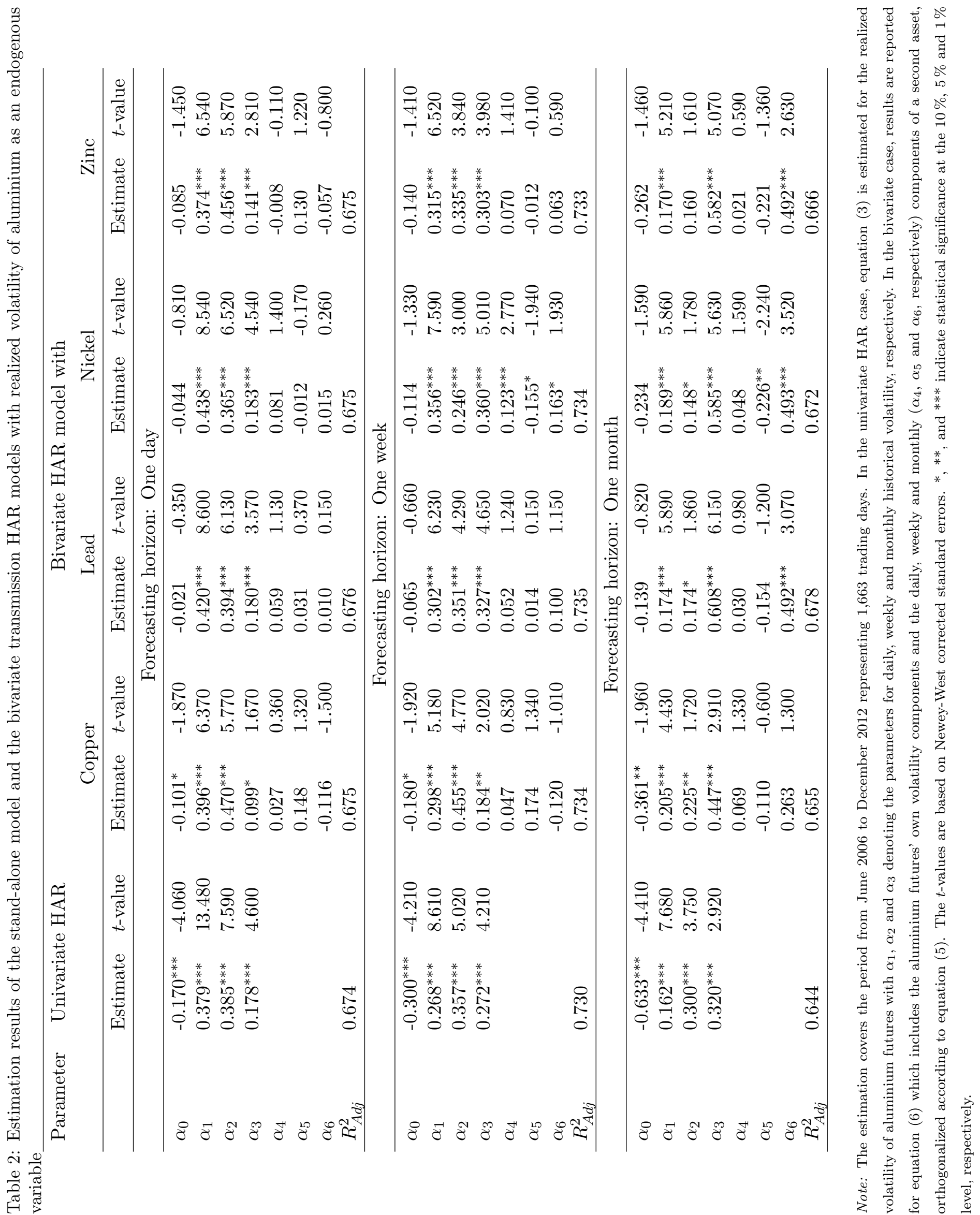






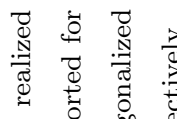

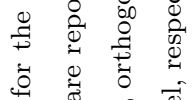

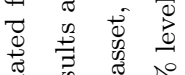
要 की 요

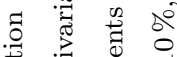
范曾

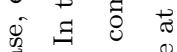
争 在宽密

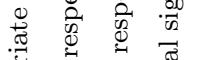
题 政需 घ.

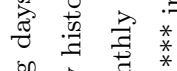

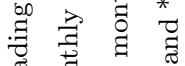
政 照

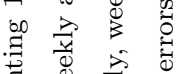

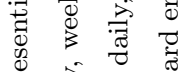

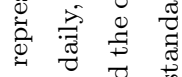
तै 㕝 त) $\begin{array}{ll}2 & 0 \\ 0 & 0 \\ 0 & 0 \\ 0 & 0 \\ 0 & 0 \\ 0 & 0\end{array}$ ฮี้

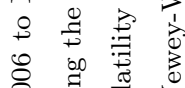
总 政

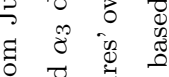
苟藏善 )

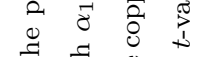
青要

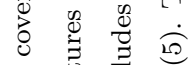
童带

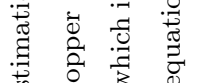
० प0

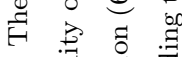

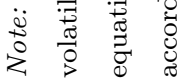




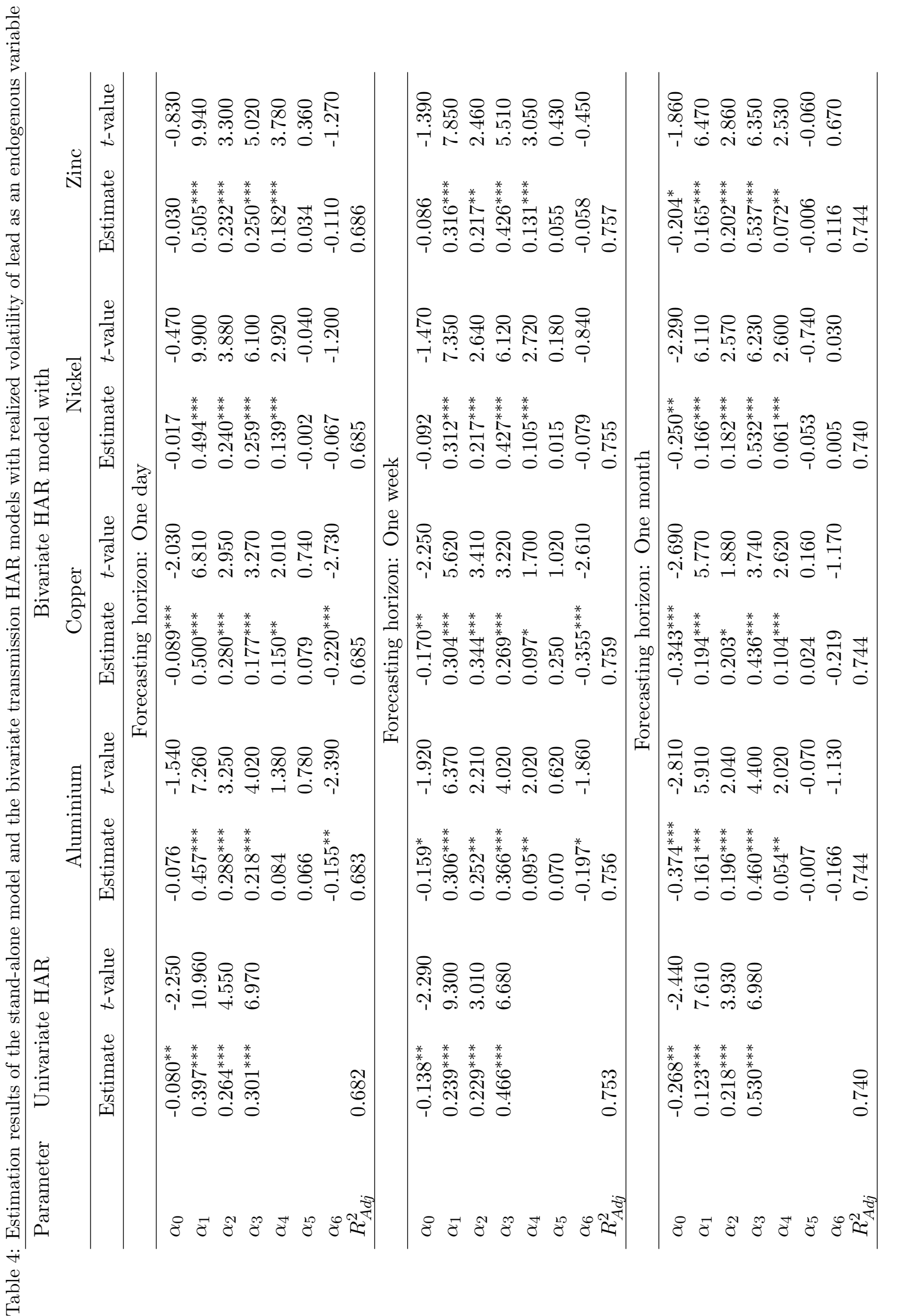

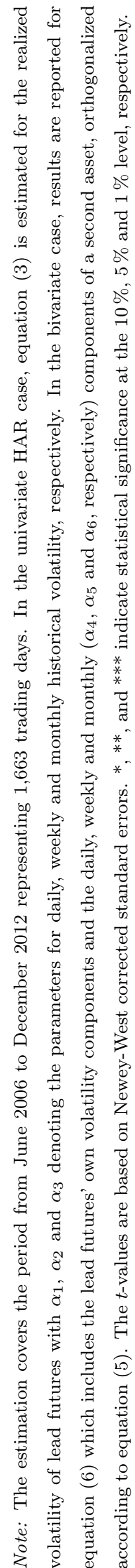




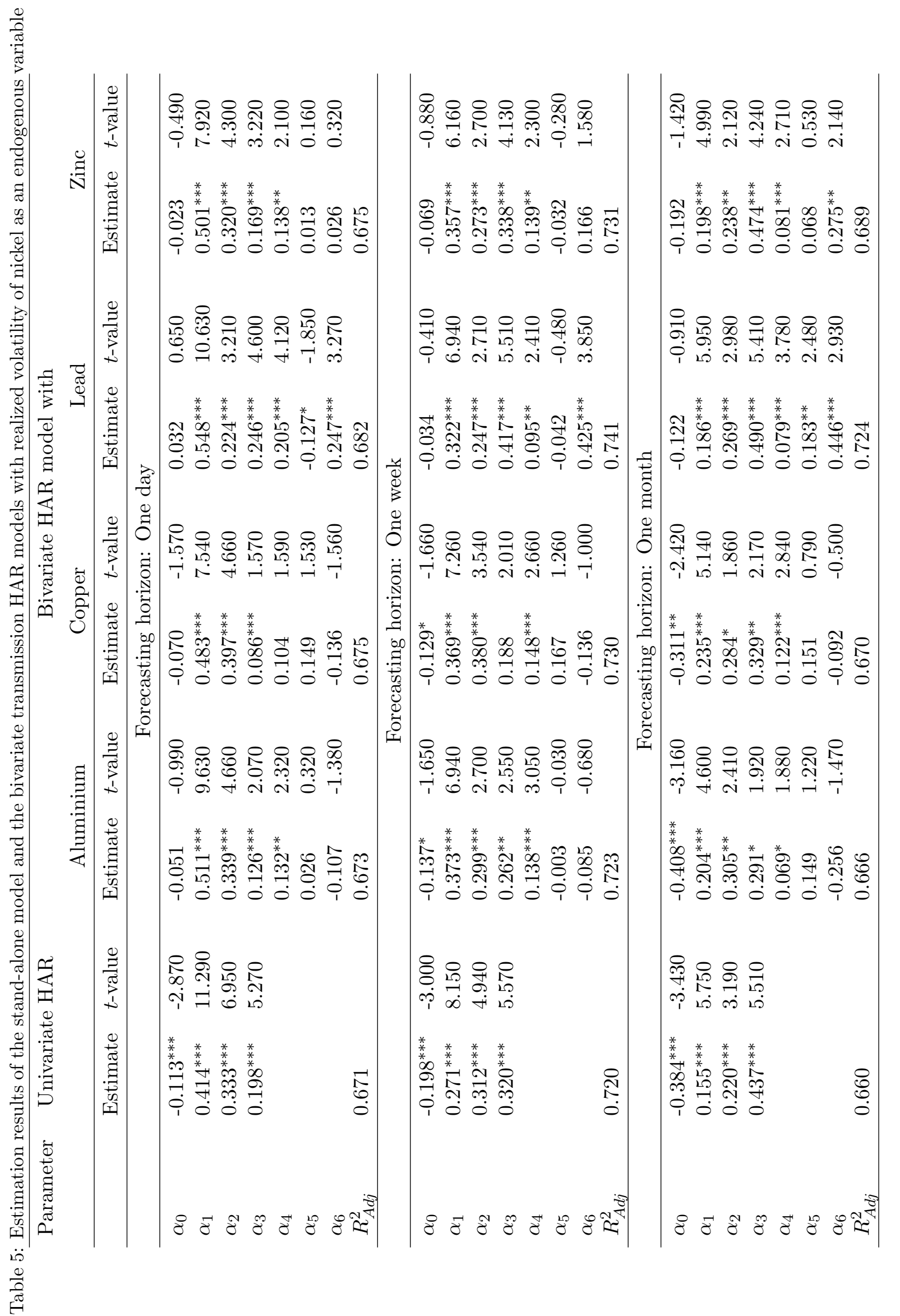

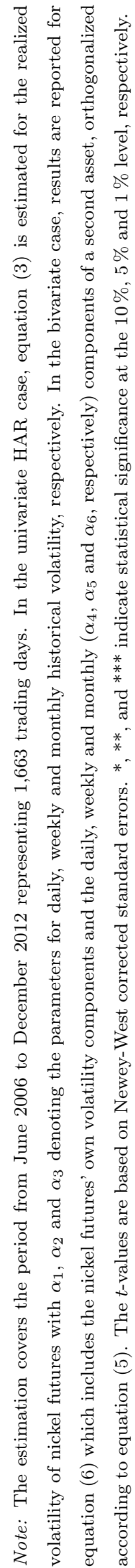




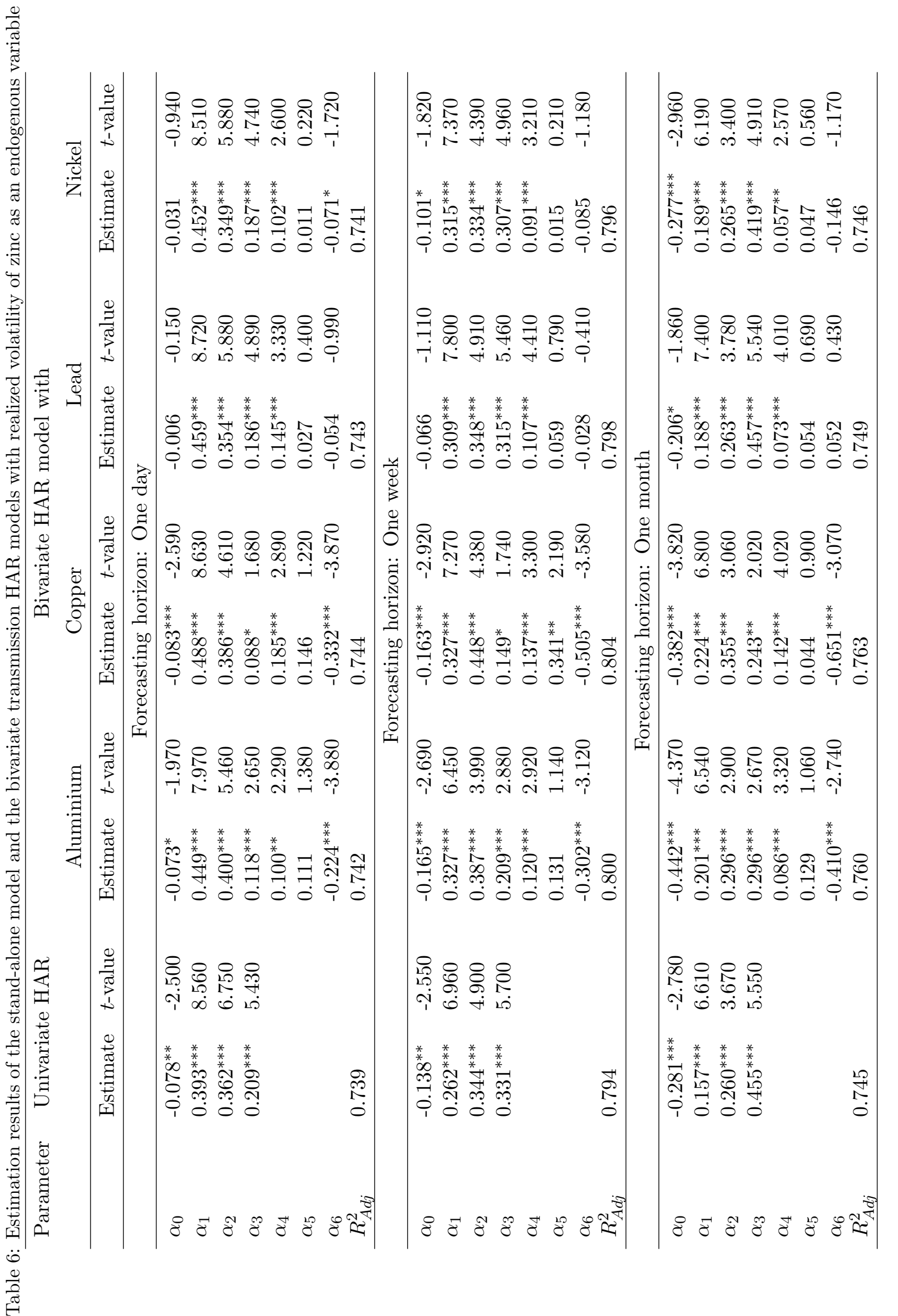

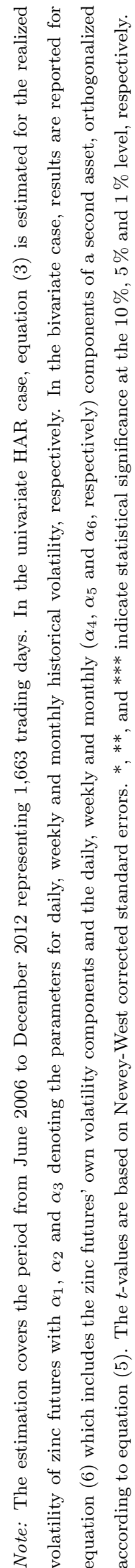



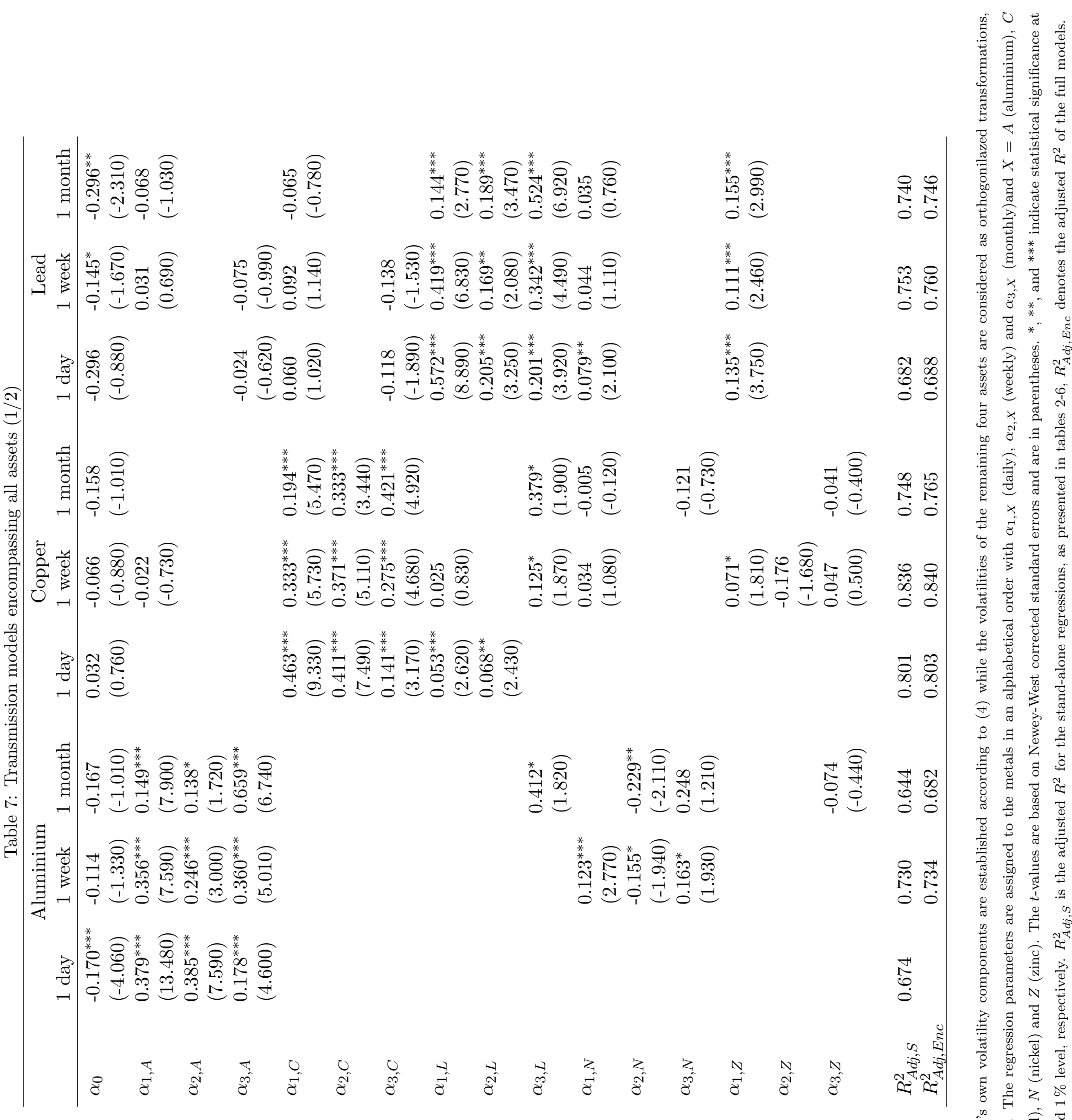


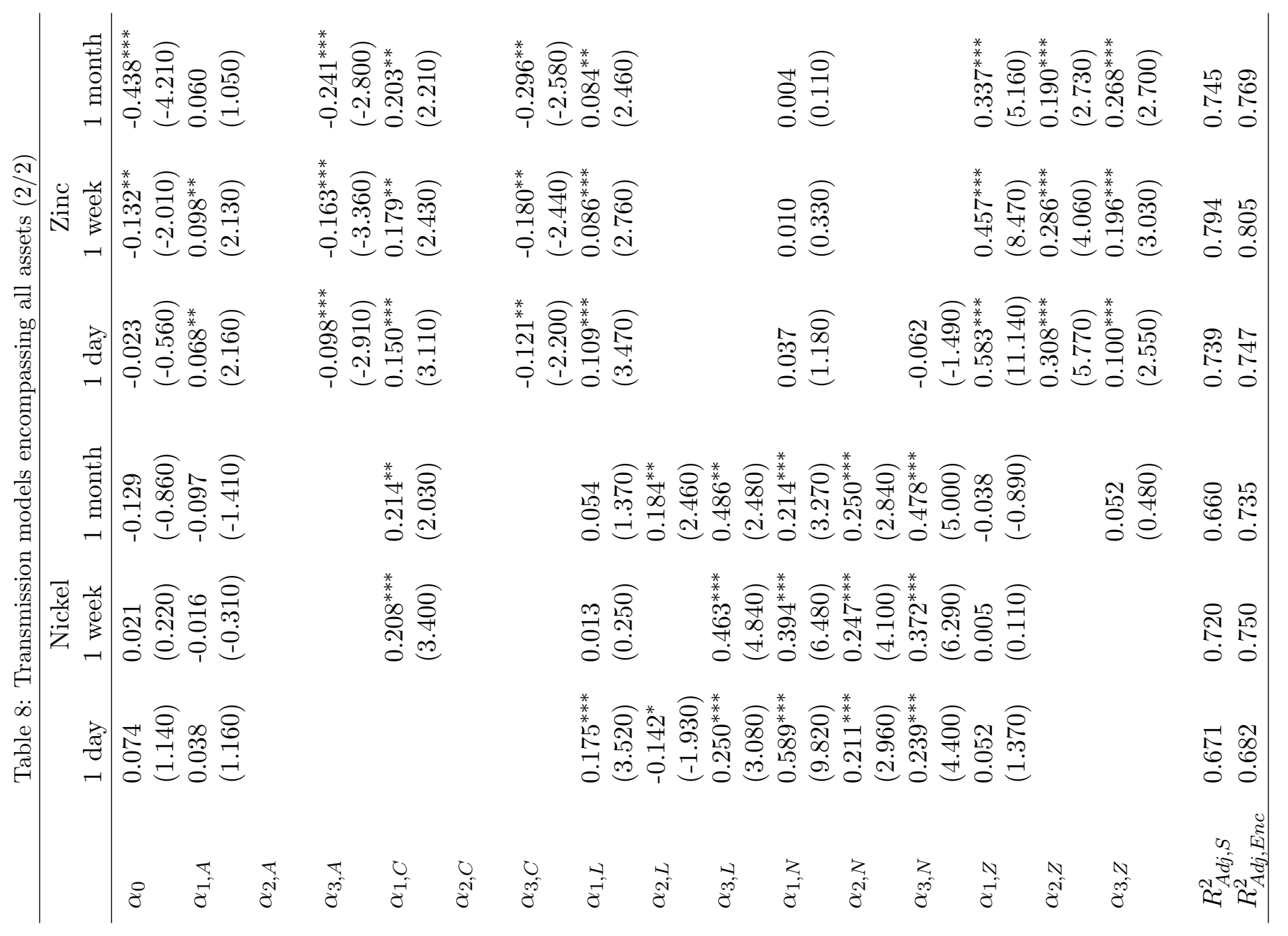

